\title{
Design, Realization and Measurements of a Miniature Antenna for Implantable Wireless Communication Systems
}

\author{
Francesco Merli, Member, IEEE, Léandre Bolomey, Jean-François Zürcher, Giancarlo Corradini,
} Eric Meurville, and Anja K. Skrivervik

\begin{abstract}
The design procedure, realization and measurements of an implantable radiator for telemetry applications are presented. First, free space analysis allows the choice of the antenna typology with reduced computation time. Subsequently the antenna, inserted in a body phantom, is designed to take into account all the necessary electronic components, power supply and bio-compatible insulation so as to realize a complete implantable device. The conformal design has suitable dimensions for subcutaneous implantation $(10 \times 32.1 \mathrm{~mm})$. The effect of different body phantoms is discussed. The radiator works in both the Medical Device Radiocommunication Service (MedRadio, 401-406 MHz) and the Industrial, Scientific and Medical (ISM, 2.4-2.5 GHz) bands. Simulated maximum gains attain -28.8 and $-18.5 \mathrm{dBi}$ in the two desired frequency ranges, respectively, when the radiator is implanted subcutaneously in a homogenous cylindrical body phantom $(80 \times 110 \mathrm{~mm})$ with muscle equivalent dielectric properties. Three antennas are realized and characterized in order to improve simulation calibration, electromagnetic performance, and to validate the repeatability of the manufacturing process. Measurements are also presented and a good correspondence with theoretical predictions is registered.
\end{abstract}

Index Terms-Biocompatible antenna, dual band, implanted antennas, Medical Device Radiocommunication Service (MedRadio), miniature antenna, multilayered PIFA, spiral antenna.

\section{INTRODUCTION}

$\mathbf{W}$ IRELESS implantable systems promise large improvements in patients' care and quality of life. Pacemaker communication, glucose monitoring, insulin pumps and endoscopy are just a few examples of medical treatments that could take advantage of wireless control [1]. The Medical Device Radiocommunication Service band (MedRadio, 401-406 $\mathrm{MHz}$ ) has been recently allocated [2] to this purpose. Among all the components necessary for implanted telemetry applications, the antenna plays a key role in obtaining robust communication

Manuscript received July 01, 2010; revised December 20, 2010; accepted February 28, 2011. Date of publication August 04, 2011; date of current version October 05, 2011.

F. Merli, J.-F. Zürcher and A. K. Skrivervik are with the Laboratoire d'Electromagnétisme et d'Acoustique (LEMA), Ecole Polytechnique Fédérale de Lausanne (EPFL), CH-1015 Lausanne, Switzerland (e-mail: francesco.merli@epfl. ch).

L. Bolomey, G. Corradini and E. Meurville are with the Laboratoire de Production Microtechnique (LPM2), Ecole Polytechnique Fédérale de Lausanne (EPFL), CH-1015 Lausanne, Switzerland (e-mail: leandre.bolomey@epfl.ch).

Color versions of one or more of the figures in this paper are available online at http://ieeexplore.ieee.org.

Digital Object Identifier 10.1109/TAP.2011.2163763 links and a significant miniaturization of the whole device. In fact, the design of an electrically small radiator (with reduced efficiency and bandwidth) in the presence of a "hostile" environment such as the human body is a challenging task. Several implantable radiators, with different characteristics and target applications, have been recently presented. Among others, an ultra-wideband compact design $(3.5-4.5 \mathrm{GHz})$ is discussed in [3], whilst a conformal design for an ingestible application at $1.4 \mathrm{GHz}$, of limited lifetime, is introduced in [4]. Cavity slot radiators without integration with active components are presented for the Industrial, Scientific and Medical band (ISM, 2.4-2.5 GHz) for on-body and in-body applications in [5] and [6], respectively. In the same frequency range, in-vitro and in-vivo tests of an implantable antenna for intracranial pressure monitoring are performed in [7], [8], whereas retinal prothesis applications are investigated with miniature antennas in [9], [10]. Focusing on designs operating within the MedRadio band, planar meander and spiral structures are compared in [11], [12]. Extensive analysis of this kind of antenna typology (including the effect of different dimensions and materials) is also reported in [13], [14]. Finally, a dual band antenna, including the MedRadio band, is presented in [15] with possible subcutaneous rat implantation in [16]. The latter radiator, although planar with sharp edges, shows a remarkable high gain, achieved with the use of the particle swarm optimization method.

This work focuses on the design procedure and the realization of an implantable dual band antenna, working in both the MedRadio and the ISM, $(2.4-2.5 \mathrm{GHz})$ bands. The radiator is designed to be integrated with all the required active components [17] and bio-sensors or actuators so as to form a complete generic implantable wireless telemetry system [18]. An example of a potential application is an implantable glucose monitoring system with a 1-year life time [19]. The proposed design overcomes several issues, further described in Section II, leading to the realization and measurement of a successful implantable telemetry system for in-vitro (biology/chemistry) and in-vivo (medicine) applications.

The manuscript is organized as follows: Section II describes the physical constraints and electromagnetic specifications required for the antenna design. The equivalent human body model is also introduced. The design procedure and the solution adopted are reported in Section III, along with the investigation of the robustness of the radiator against the presence of the active components and the insertion in different body models. 
Sections IV and V detail the fabrication and the measurements of the prototypes, respectively. The latter pays particular attention to the effect of the feeding cable used for testing purposes. Finally, the obtained results are summarized in Section VI.

\section{ANTENNA REQUiREMENTS AND BODY MODELING}

In order to perform the antenna design for a complete active implantable system, several aspects must be taken into account. These aspects may be classified into physical constraints and electromagnetic (EM) specifications. Such classification will be helpful to understand how we developed the design procedure and achieved the final structure. Moreover, the equivalent human body model is chosen at the initial stage of the work, as it strongly influences the antenna design.

\section{A. Physical Constraints}

- The volume of the entire implant (i.e., the antenna, insulation, electronics, batteries and biosensors) must fit in a cylindrical housing. A maximum external diameter of 10 $\mathrm{mm}$ is set to allow subcutaneous implantation in rats [20];

- bio-compatible insulation must embed the implantable device. The insulation avoids adverse tissue reaction [21], short-circuiting effects due to highly conductive human body tissues, and it is also very valuable for telemetry applications [3], [7], [13], [22], [23];

- a dense packaging is required to reduce the implant volume [17], hence the antenna feeding point is placed in a small predefined area to minimize the circuitry complexity;

- the actual process of antenna manufacturing has to be taken into account in order to avoid extremely tight tolerances and to maximize the repeatability of the construction process itself.

\section{B. Electromagnetic Specifications}

- Dual band capability must be obtained to operate with the transceiver produced by Zarlink Semiconductors [24]. Such capability minimizes power consumption as the sensor can be awoken from sleeping state by receiving a signal in the $2.4-2.5 \mathrm{GHz}$ band. Subsequently, data transmission occurs only in the MedRadio frequency range;

- a single antenna feeding point is targeted to minimize the assembly complexity;

- antenna gains higher than -30 and $-20 \mathrm{dBi}$ are targeted in the MedRadio band and the ISM band, respectively. Note that these gain values include both the antenna radiation characteristics and the simulated body phantom presence. The corresponding radiation efficiencies are rather small, but they provide operational ranges wider than $10 \mathrm{~m}$ in the MedRadio and $5 \mathrm{~m}$ in the ISM bands, with the use of the Zarlink transceiver and base station. These performances will result in an excellent communication in the targeted $2 \mathrm{~m}$ distance [24].

- EM performance has to be robust against the battery and electronics presence;

- implant location in the human body must have little effect on the EM performance.

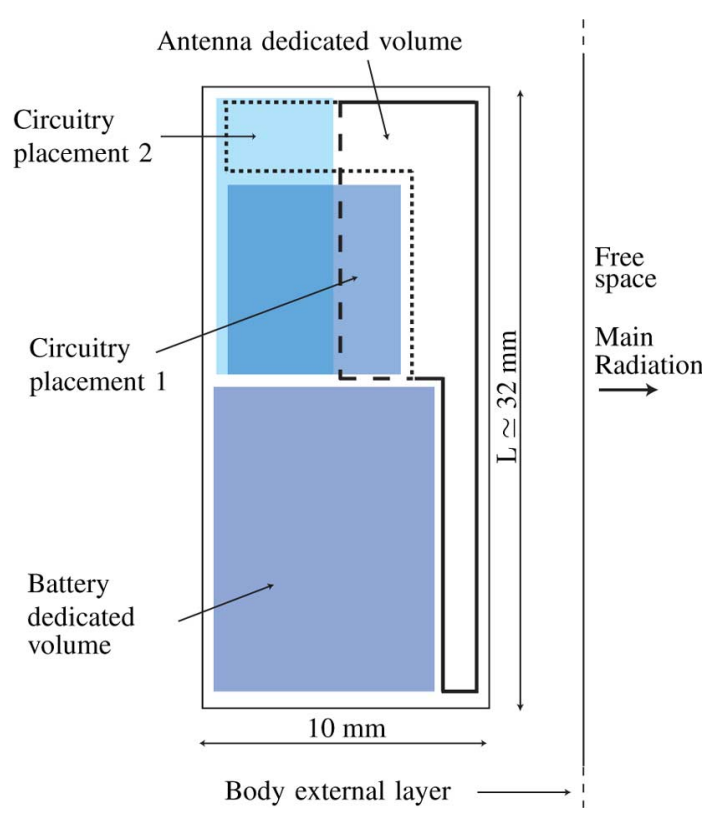

Fig. 1. Implanted sensor conception. Maximum dimensions are indicated Placements of battery and electronics are indicated to estimate the overall volume occupancy; two possible geometries of the circuitry (in light colors), and consequently of the antenna (solid-dashed lines), are shown.

\section{Human Body Modeling}

Several possibilities of body phantoms, i.e., equivalent human body models, are nowadays available with different complexities; examples can be found in [9], [25]-[27]. Nevertheless, the realization of a single body phantom for frequency ranges as different as the MedRadio and ISM bands, is still remarkably hard [15]. For instance, wide band phantoms are available for a higher frequency spectrum [28] and a broad frequency range is realized only with skull equivalent properties in [29]. In this work we decided to follow the recommendations of [30] using a simple homogeneous cylinder with muscle-like dielectric properties whose values are taken from [31], for each frequency band. The approximation is rather rough, but it does allow to reduce the simulation time, and it provides standard and easy to realize conditions for the radiator measurements.

\section{AnTENNA Design}

In order to overcome all constraints and to meet all requirements, the design procedure follows the next steps:

- Design the antenna in free space [4], [32] in the absence of dielectric substrates and body phantom. Two main reasons can be given. First, assuming there is no surrounding medium reduces significantly the computation time. Therefore it allows a faster rough design to select an efficient antenna typology, given the available volume. Second, it is important to ignore the body losses at this stage in order not to optimize the antenna bandwidth by just increasing the power lost in the body;

- set the allowed excitation area, and consequently arrange the chosen antenna typology;

- add the dielectric substrate, bio-compatible insulation and body phantom, and then tune accordingly the design; 


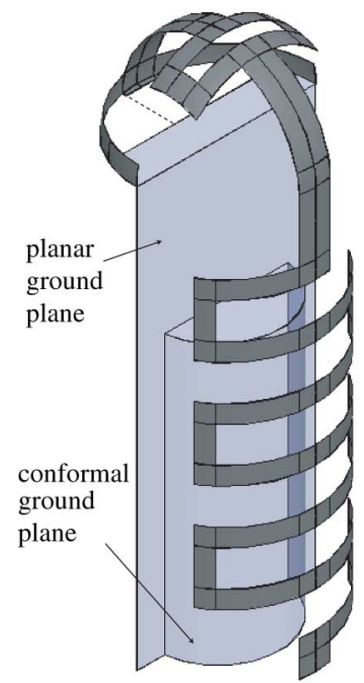

(a)

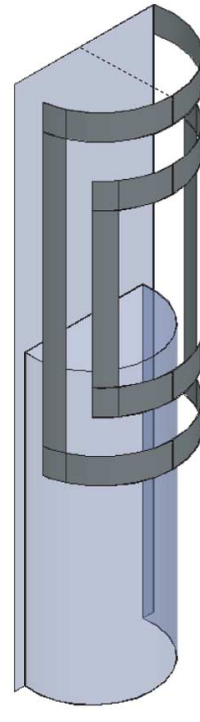

(b)

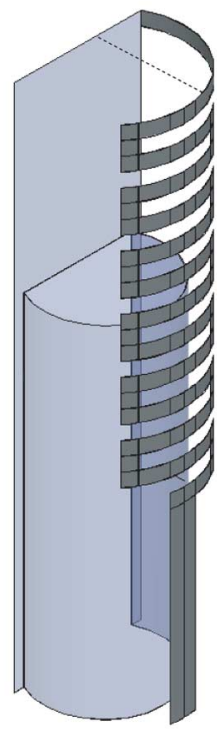

(c)

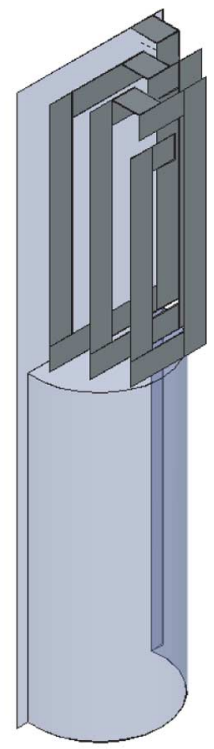

(d)

Fig. 2. First investigated typologies in free space: (a) spherical, (b) spiral, (c) meander and (d) multilayered. The ground plane (in light color), always consists of a rectangular section and a conformal part (half hollow cylinder), as indicated for the (a) case. Delta-gap excitations are indicated with dashed lines.

— modify the design in order to obtain the dual band performances.

This procedure, performed with Ansoft HFSS, aims at selecting the most efficient radiator in the MedRadio band as the medical data transmission occurs there. We decided to focus on the radiation properties in the lower frequency range despite reduced, but still adequate, performances in the ISM band. Indeed, higher radiation performances can be obtained at $2.45 \mathrm{GHz}$, as presented in [15], with different constraints.

Section III-A presents the free space analysis, while the selected typology is described in Section III-B. In accordance with the EM requirements, Section III-C discusses the design robustness against the active components presence, and we analyzed the use of other two body phantoms. The latter provides insights about the sensitivity of the proposed design versus different implant locations.

\section{A. Selection of the Antenna Typology in Free Space}

The overall implant concept is depicted in Fig. 1. It has a cylindrical volume (diameter: $10 \mathrm{~mm}$, height: $32 \mathrm{~mm}$ ). The battery and two circuitry placements, indicated in Fig. 1, are offcentered with respect to the cylinder axis. In order to reduce the interference due to the active components on the antenna's behavior, we considered a ground plane made of a rectangular planar section and a half hollow cylinder part (both depicted in light color in Fig. 2). At the same time this solution, together with its off-centered design, enhances the directivity of the radiator towards the desired out-of-the body direction, and it has the advantage of reducing the power absorbed by the biological tissues. For an easier understanding, the half hollow cylinder part has been referred to as conformal ground plane in Sections IV-VI of the manuscript.

Four different typologies, depicted in Fig. 2, were investigated: spherical (conceived for the circuitry placement 1 in Fig. 1), spiral, meander and multilayered (for the circuitry
TABLE I

COMPARISON OF THE RADIATION PERFORMANCES FOR Four ANTENNA Typologies in Free Space. Max Values are REPORTED FOR BOTH GAIN AND DIRECTIVITY

\begin{tabular}{l|c|c|c|c}
\hline Typology & $\begin{array}{c}\text { Res. Freq. } \\
{[\mathbf{G H z}]}\end{array}$ & $\begin{array}{c}\text { Gain } \\
{[\mathbf{d B i}]}\end{array}$ & $\begin{array}{c}\text { Directivity } \\
{[\mathbf{d B i}]}\end{array}$ & $\begin{array}{c}\text { Rad. Eff. } \\
{[\%]}\end{array}$ \\
\hline \hline Spherical & 1.035 & -7.6 & 1.2 & 13.182 \\
\hline Spiral & 1.029 & -3.8 & 1.8 & 27.542 \\
\hline Meander & 1.038 & -7.9 & 1.3 & 12.022 \\
\hline Multilayered & 1.058 & -1.8 & 1.8 & 43.651 \\
\hline
\end{tabular}

placement 2 in Fig. 1). All designs have a ground connection (like in PIFA antennas) in order to further reduce the resonant frequency. An extensive study of the indicated typologies was performed to choose an efficient antenna structure, given the available volume, with fast computation performance. Radiation characteristics and current vector alignments concept [10], [33], [34] were considered in this study.

Table I reports the performance of these four typologies; only one result per typology that can be considered as a reference for all the evaluated designs is given. The single resonant frequency is chosen at around $1 \mathrm{GHz}$. The dielectric loading effect (due to the presence of dielectric substrates, bio-compatible insulation and body phantom that are considered in the second step of the design procedure) will consequently shift the resonant frequency towards lower frequencies, close to the MedRadio band. Only ohmic losses are taken into account (copper $17 \mu \mathrm{m}$ thick). As previously discussed, bandwidth performances are not considered at this stage of the design procedure.

The spherical case provides a more accentuated omnidirectional radiation (lowest directivity) without any remarkable efficiency. Thus, we considered the other three typologies, sharing the same antenna dedicated volume indicated in Fig. 1, so as to facilitate the radiation in the desired direction. 


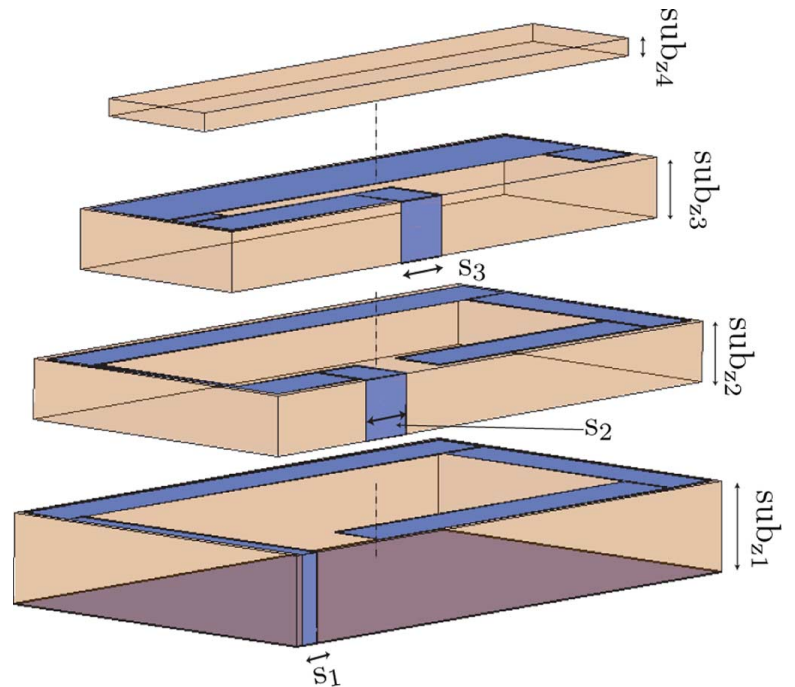

Fig. 3. Assembling of the 4 ROGER TMM substrates to create a pyramidal structure. Spiral metallization is in dark color. $s_{1,2,3}$ are the widths of the vertical metallizations whose dimensions are given in Table II. The four substrates are separated for a better comprehension.

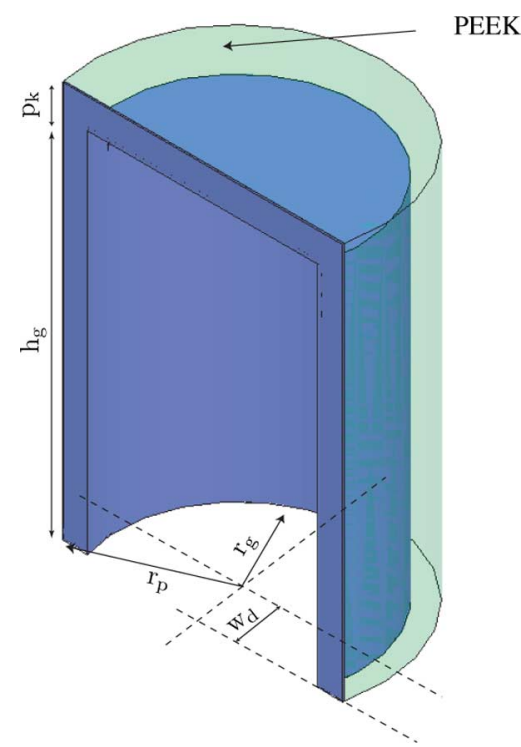

Fig. 4. Conformal ground plane: half hollow cylindrical structure to house the batteries. Metallization of the PEEK piece is made of copper foil $0.05 \mathrm{~mm}$ thick (dark color). Dimensions are given in Table II.

The spiral design increases the radiation efficiency and directivity compared to the meander case, in agreement with [9], [12], [13]. However, both metallizations of these two typologies (depicted in dark gray in Fig. 2) reach over the region dedicated to the battery housing. The very small distance between the ground plane and the metallizations does not facilitate the radiation.

On the other hand, the multilayered solution achieves the desired resonance by utilizing only the uppermost part of the volume. This aspect, combined with the spiral conception, provides the most performing typology, both in directivity and efficiency, for the targeted application. Furthermore, the multilayered structure presents the simplest realization process; therefore this typology was selected for the making of the design.

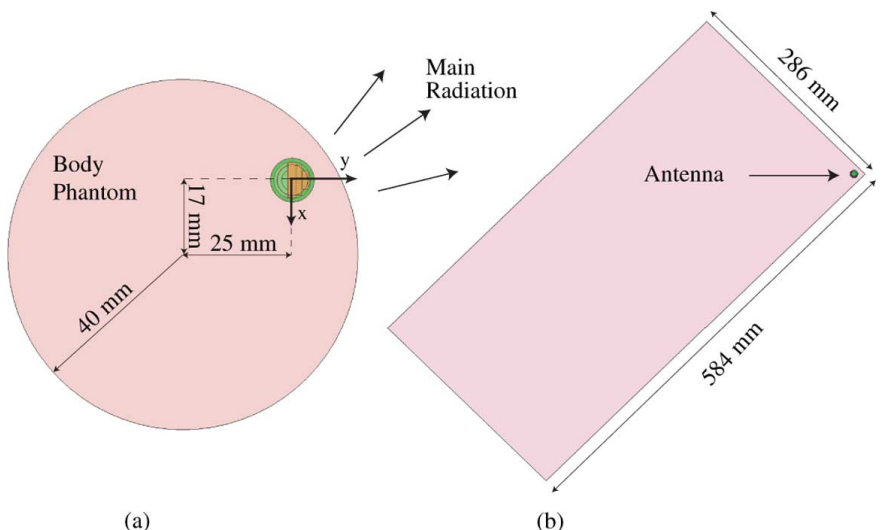

(a)

(b)

Fig. 5. Antenna off-centered placement in (a) the homogeneous cylindrical body phantom (at the middle of its height) to mimic subcutaneous implantation. The study of (b) a larger box phantom is discussed in Section III-C-III.

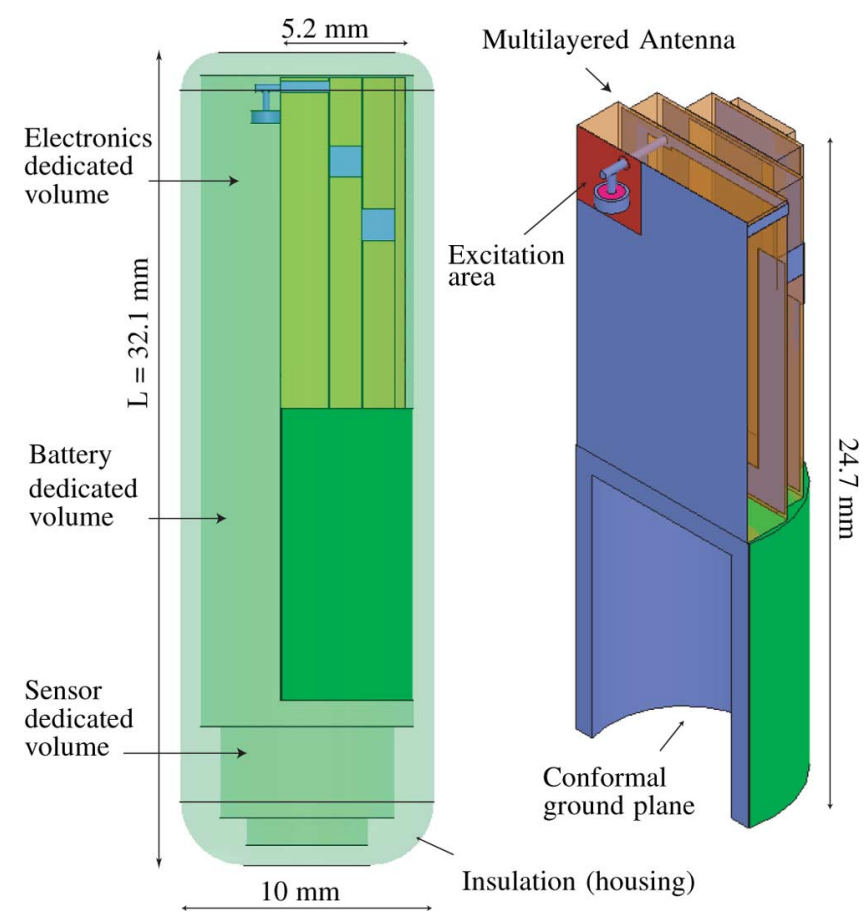

Fig. 6. Design of the proposed prototype. The conformal antenna and its housing allow for the placement of all the necessary components for the sensor control, data processing, communication and power supply.

\section{B. Multilayered Antenna Design}

The multilayered spiral model is built by pyramidal assembling to comply with the physical constraints. The structure, illustrated in Fig. 3, is made of four stacked dielectric substrates. Roger TMM 10 (alumina) with $35 \mu \mathrm{m}$ copper metallization was chosen because of its high relative dielectric constant $\left(\varepsilon_{r}^{\prime}=9.2\right)$ and low loss $(\tan \delta=0.0022)$.

The pyramidal structure is united with the conformal ground plane, depicted in Fig. 4. The latter consists of a metallized half hollow cylinder made of PEEK (Polyetheretherketones, $\varepsilon_{r}^{\prime}=$ $3.2, \tan \delta=0.01)$. The choice of this material was mainly dictated by practical requirements, as it is very easy to manufacture as well as to metallize. 


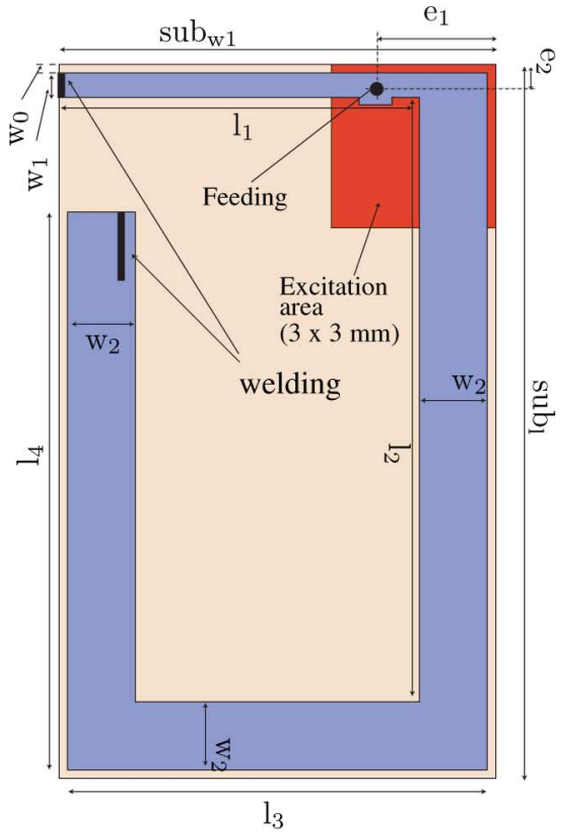

(a)

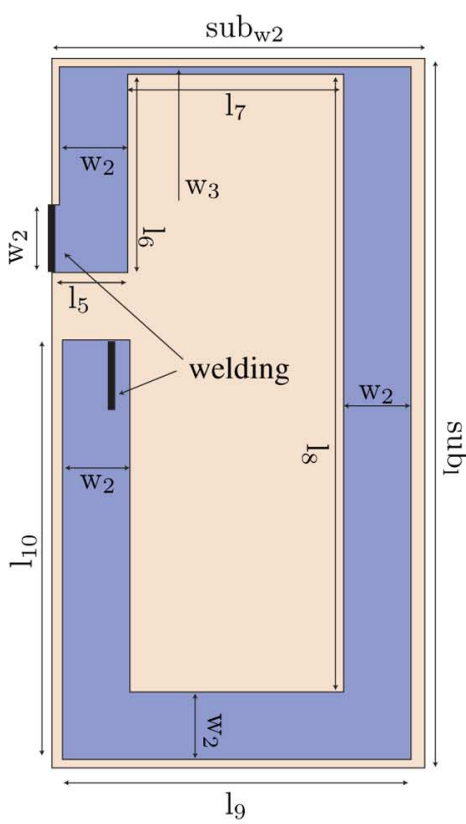

(b)

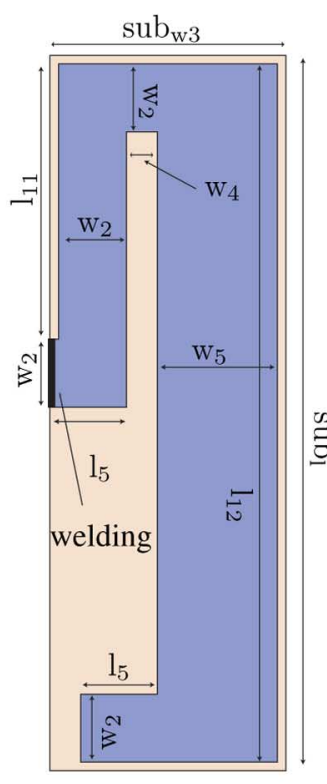

(c)

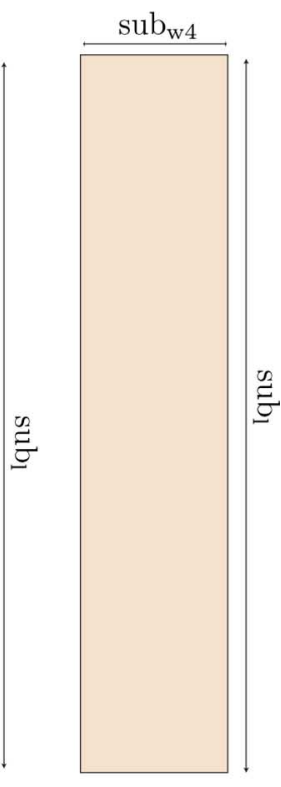

(d)

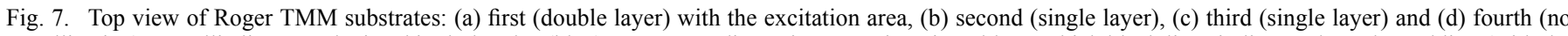

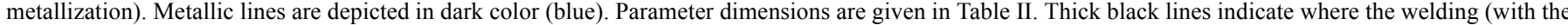
vertical metallizations) occurs.

At this stage of the design procedure, the antenna was integrated with the bio-compatible insulation and inserted into the body phantom. The former is made of PEEK because of its bio-compatibility and excellent mechanical, thermal and chemical resistance. Its thickness was set to just $0.8 \mathrm{~mm}$ to maximize the volume for the antenna design, in accordance with [22]. The human model has dielectric properties similar to muscle tissue whose values are given in Table IV. Its radius and height are equal to 40 and $110 \mathrm{~mm}$, respectively. To mimic the targeted subcutaneous implantation, the antenna placement in the cylindrical body phantom was off-centered, as illustrated in Fig. 5(a).

Once the excitation area was set by the physical constraints, we optimized (with a trial and error procedure) the dimensions of the multilayered spiral metallization in order to achieve the desired performance. Fig. 6 depicts the final radiator, including its bio-compatible housing. The overall volume of the implantable device is equal to $2477 \mathrm{~mm}^{3}$; only approximately $24 \%$ of it is allocated to the radiator. This results in an electrically very small antenna in the MedRadio band $(\lambda / 13$ referring to the insulation dielectric properties [35, chapter 5]). For a better comprehension of the design, the four substrates are illustrated in Fig. 7, while Table II reports the values all the geometrical parameters. The limited area for excitation, due to the electronics constraints, is clearly indicated in Figs. 6 and $7(\mathrm{a})$.

\section{Simulated EM Characteristics}

Several results are presented in the following parts. For an easier understanding, Table III summarizes the obtained performances.

1) Matching and Radiation: Reflection coefficients versus frequency, $\left|S_{11}(f)\right|$, are plotted in Fig. 8. It can be noted that, while the antenna is well matched in the MedRadio frequency
TABLE II

Values of the Design Parameters IndiCATed in Figs. 3-7

\begin{tabular}{c|c||c|c}
\hline Parameter & Value [mm] & Parameter & Value [mm] \\
\hline \hline $\mathrm{sub}_{\mathrm{w} 1}$ & 8.000 & $\mathrm{w}_{5}$ & 2.200 \\
\hline $\mathrm{sub}_{\mathrm{w} 2}$ & 6.900 & $\mathrm{l}_{1}$ & 6.617 \\
\hline $\mathrm{sub}_{\mathrm{w} 3}$ & 4.300 & $\mathrm{l}_{2}$ & 11.100 \\
\hline $\mathrm{sub}_{\mathrm{w} 4}$ & 2.700 & $\mathrm{l}_{3}$ & 7.700 \\
\hline $\mathrm{sub}_{\mathrm{z} 1}$ & 1.905 & $\mathrm{l}_{4}$ & 10.250 \\
\hline $\mathrm{sub}_{\mathrm{z} 2}$ & 1.270 & $\mathrm{l}_{5}$ & 1.400 \\
\hline $\mathrm{sub}_{\mathrm{z} 3}$ & 1.270 & $\mathrm{l}_{6}$ & 3.650 \\
\hline $\mathrm{sub}_{\mathrm{z} 4}$ & 0.381 & $\mathrm{l}_{7}$ & 4.000 \\
\hline $\mathrm{sub}_{1}$ & 13.100 & $\mathrm{l}_{8}$ & 11.400 \\
\hline $\mathrm{w}_{1}$ & 0.450 & $\mathrm{l}_{9}$ & 6.450 \\
\hline $\mathrm{w}_{2}$ & 1.250 & $\mathrm{l}_{10}$ & 7.750 \\
\hline $\mathrm{w}_{3}$ & 0.150 & $\mathrm{l}_{11}$ & 5.050 \\
\hline $\mathrm{w}_{4}$ & 0.550 & $\mathrm{l}_{12}$ & 12.800 \\
\hline $\mathrm{e}_{1}$ & 2.200 & $\mathrm{e}_{2}$ & 0.450 \\
\hline $\mathrm{h}_{\mathrm{g}}$ & 10.750 & $\mathrm{p}_{\mathrm{k}}$ & 0.800 \\
\hline $\mathrm{r}_{\mathrm{p}}$ & 5.000 & $\mathrm{r}_{\mathrm{g}}$ & 3.500 \\
\hline $\mathrm{w}_{\mathrm{d}}$ & 1.000 & $\mathrm{w}_{0}$ & 0.150 \\
\hline $\mathrm{s}_{1}$ & 0.450 & $\mathrm{~s}_{2,3}$ & 1.250 \\
\hline & & & \\
\hline & & & \\
\hline
\end{tabular}

range (with a $2.3 \%$ relative band), the higher resonance is slightly lower (i.e., $2.387 \mathrm{GHz}$ ) than the targeted $2.45 \mathrm{GHz}$. Nevertheless, the simulated $\left|S_{11}(f)\right|$ shows a wide working band $(6 \%$ at $-10 \mathrm{~dB}$ points) that includes a sufficient part of the desired ISM frequency spectrum.

3D polar plots are reported in Fig. 9. The maximum gain values are, taking the body phantom into account, -28.8 and $-18.5 \mathrm{dBi}$ at MedRadio and at ISM bands, respectively. 
TABLE III

Summary of the Simulated Results of the Proposed RADIATOR IN DIFFERENT BODY PHANTOMS

\begin{tabular}{l|c|c|c}
\hline $\begin{array}{l}\text { Phantom } \\
\text { at 404.5 } \mathbf{~ M H z ~}\end{array}$ & $\begin{array}{c}\text { Real. Gain } \\
\text { [dBi] }\end{array}$ & $\begin{array}{c}\text { Directivity } \\
\text { [dBi] }\end{array}$ & $\begin{array}{c}\text { Rad. Eff. } \\
\text { [\%] }\end{array}$ \\
\hline \hline cyl. muscle & -28.8 & 3.6 & 0.058 \\
\hline cyl. muscle \& battery & -28.6 & 3.6 & 0.060 \\
\hline cyl. head & -30.4 & 3.5 & 0.040 \\
\hline cyl. 3-layered & -31.3 & 3.6 & 0.041 \\
\hline box muscle & -28.4 & 2.6 & 0.078 \\
\hline \hline at 2.387 GHz & & & \\
\hline \hline cyl. muscle & -18.5 & 4.2 & 0.530 \\
\hline cyl. muscle \& battery & -18.6 & 4.3 & 0.507 \\
\hline cyl. head & -17.7 & 4.2 & 0.647 \\
\hline cyl. 3-layered & -16.3 & 4.2 & 0.883 \\
\hline
\end{tabular}

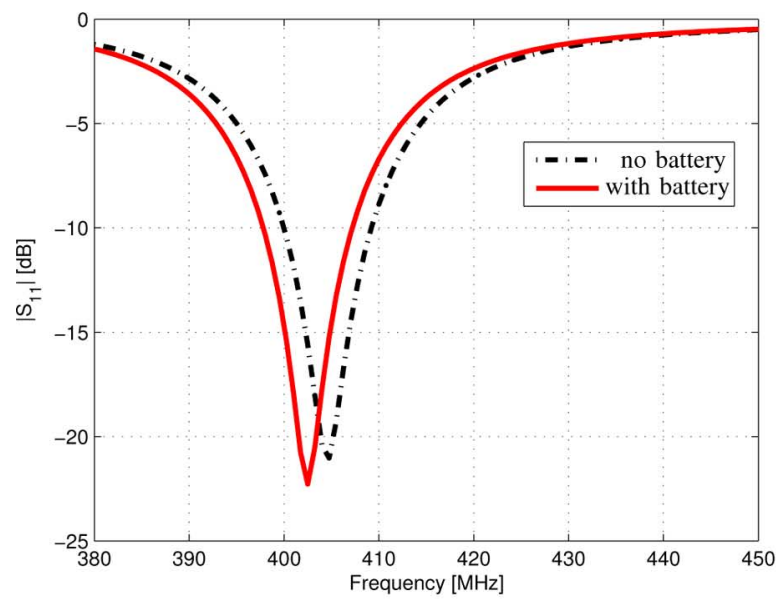

(a)

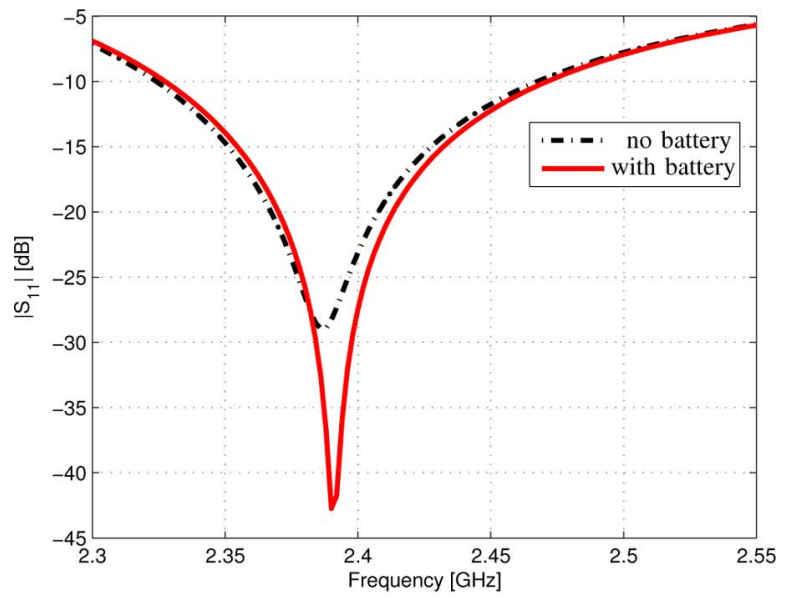

(b)

Fig. 8. Simulated $\left|S_{11}(f)\right|$ against frequency. The effect of the presence of the battery (and electronics) is compared with the reference design (no battery): (a) MedRadio and (b) ISM bands.

Despite the higher attenuation of the electromagnetic field in muscle at higher frequency, the radiator is much more efficient in the ISM band, as its size is electrically larger than in the MedRadio range. Surface current distributions are illustrated in

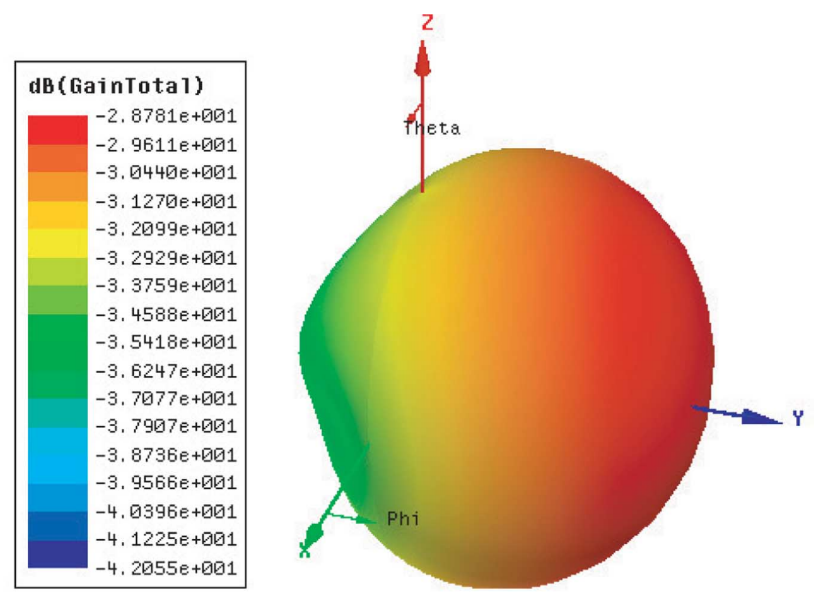

(a)
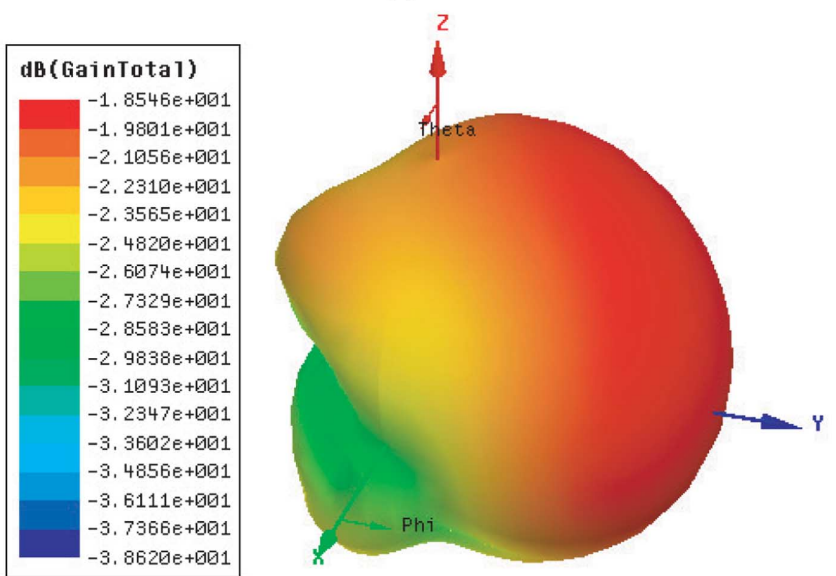

(b)

Fig. 9. Simulated 3D gain polar plot at: (a) $404.5 \mathrm{MHz}$ and (b) $2.387 \mathrm{GHz}$. Radiation efficiencies are $0.058 \%$ and $0.530 \%$, respectively. Coordinate system is the same as in Fig. 5(a)

Fig. 10; as expected, almost the whole multilayered structure is relevant in the MedRadio range while some cold zones can be identified when the antenna dimensions are electrically larger, i.e., in the ISM band.

2) Design Robustness Against the Batteries and Electronics Presence: The volumes allocated to the batteries and the circuitry placement " 2 ", depicted in Fig. 1, were filled with dielectric and metallic materials [4]. A FR-4 substrate (with microstrip lines) and a copper cylinder were included in the model to mimic the presence of the electronics and power supply, respectively. Matching performances are reported in Fig. 8. Only $0.5 \%$ and $0.17 \%$ frequency shifts resulted in the two working bands, with realized gain variations limited to $0.2 \mathrm{~dB}$ (due to minimal radiation efficiency increase, as reported in Table III). These performances confirm the valuable antenna conception and they are completely satisfying for the integration of the whole sensor.

3) Effect of Different Body Phantoms: In order to obtain insights about the sensitivity of the proposed design versus different implant locations, two cylindrical body phantoms with the following characteristics were additionally investigated:

— height: $110 \mathrm{~mm}$;

- homogeneous composition, radius equal to $40 \mathrm{~mm}$, with equivalent head model dielectric properties $\left(\varepsilon_{r}^{\prime}=43.5\right.$, 


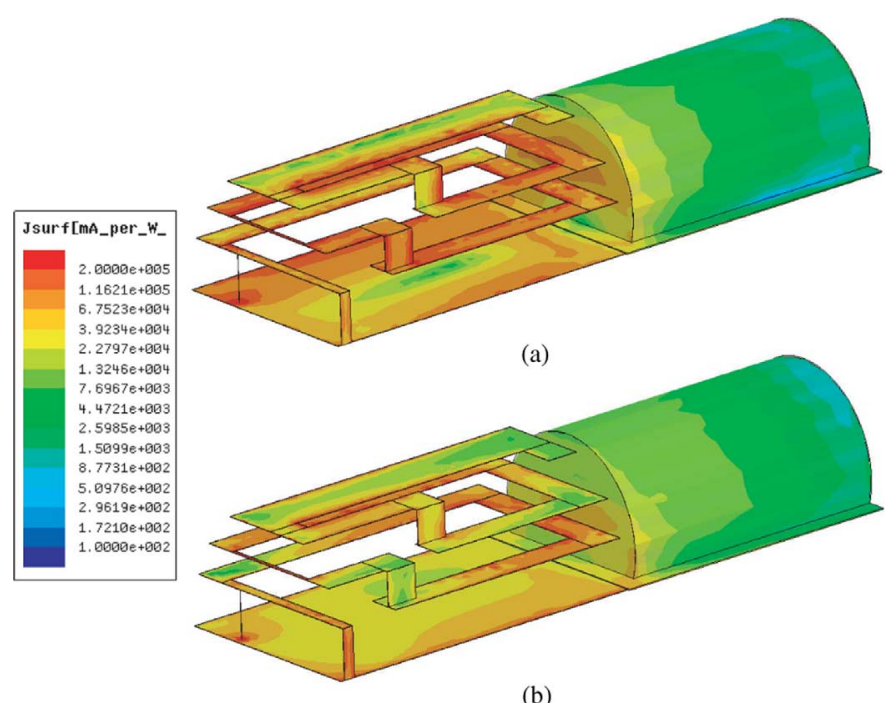

(b)

Fig. 10. Surface current distributions at (a) $404.5 \mathrm{MHz}$ and (b) $2.387 \mathrm{GHz}$.

$\tan \delta=0.799$ in the MedRadio band and $\varepsilon_{r}^{\prime}=39.2$, $\tan \delta=0.337$ at $2.45 \mathrm{GHz}$ ) [36];

- 3-layered structure made of muscle-fat-skin (dry), inspired from [11], [15], whose radii are 32,36, and $40 \mathrm{~mm}$, respectively. Dielectric properties are taken from [31] for both frequencies.

Despite the variation of the analyzed phantoms, only a maximum difference of $2.3 \%$ of the resonant frequency emerged in the MedRadio band, as reported in Fig. 11(a). We also computed the realized gain, i.e., $\left(1-\left|S_{11}(f)\right|^{2}\right) \cdot$ gain, at 404.5 MHz. Values of $-28.8,-30.4$ and $-31.3 \mathrm{dBi}$ were found for the muscle, head and multilayered phantoms, respectively. The affordable $2.5 \mathrm{~dB}$ reduction in the multilayered case is mainly due to the resonant frequency shift. Giving explanation for the decreased radiation efficiencies in the two latter models is not an easy task, especially when the radiator is electrically very small. In fact, radiation efficiency substantially depends on the nearest surrounding of the antenna (near field coupling), and the transition between the body and the free space as discussed in [22]

On the other hand, the antenna size is electrically larger in the ISM band compared to the MedRadio case. This involves a lower coupling of the near field with the lossy tissues, which results in a reduced sensitivity to the surrounding environmental conditions; the resonant frequency variation is within the $0.3 \%$ as shown in Fig. 11(b). Realized gains attain $-18.5,-17.7$, $-16.3 \mathrm{dBi}$ for the muscle, head and multilayered phantoms, respectively. Explanation about the improvement of realized gain versus different body phantoms in the ISM frequency range can be obtained by paying attention to the dielectric characteristics of the investigated models. First of all, dielectric losses: note that the maximum realized gain (and highest efficiency) is found for the multilayered model when the antenna is in close contact with fat tissue that presents the lowest $\tan \delta$ among the selected tissues [31]. Furthermore, let us pay attention to the fixed distance between the antenna and the external free space $(\approx$ $5 \mathrm{~mm}$ ). Given a constant resonant frequency (i.e., $2.387 \mathrm{GHz}$ ), this distance is electrically smaller when considering the head and multilayered models, as they are constituted by materials

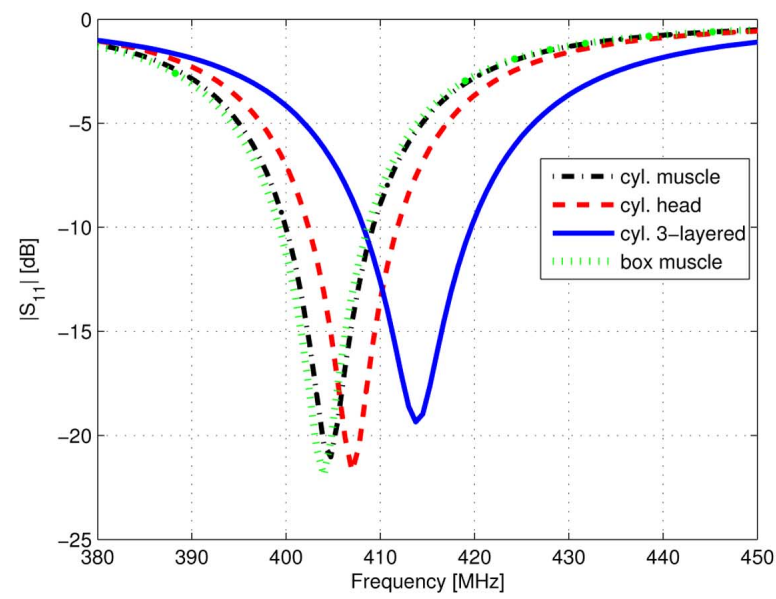

(a)

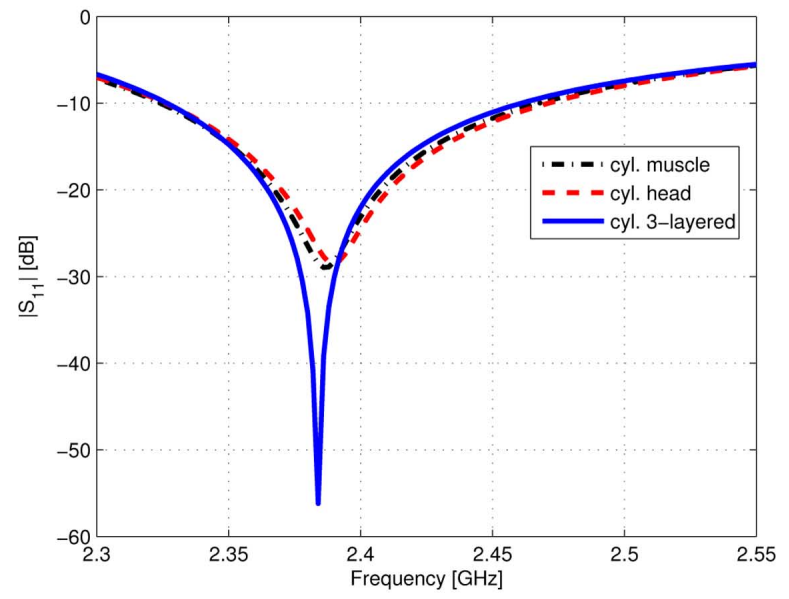

(b)

Fig. 11. Comparison of simulated $\left|S_{11}(f)\right|$ against frequency considering the antenna inserted in different body phantoms in the (a) MedRadio and the (b) ISM bands.

with lower permittivities. Thus, the radiated wave undergoes minor attenuation. As previously mentioned, these considerations do not hold true for the proposed radiator in the MedRadio range, where the higher near field coupling phenomena are the main responsible factors of the radiation efficiency.

As the cylindrical body phantom dimensions might be too small for a correct assessment of the performance of the radiator in the MedRadio range, a muscle rectangular cuboid (box) phantom with dimensions inspired from [11] (i.e., $290 \times 584 \times 320[\mathrm{~mm}]$ ) was considered. In this case the antenna was also placed at the middle of the phantom height and off-centered, $5 \mathrm{~mm}$ away from the external surfaces. This antenna location, modeling a targeted placement in the human torso above the hips, is depicted in Fig. 5(b).

Electromagnetic performances are reported in Figs. 11 and 12 and in Table III. Tolerable differences in directivity $(-1 \mathrm{~dB})$ and efficiency $(+0.02 \%)$ are found between the box and the cylindrical body phantoms. A similar realized gain $(0.4 \mathrm{~dB}$ variation $)$ and pattern (especially in the desired direction of radiation) are obtained between the two different modeled geometries. It is worth noting that the numerical analysis of the cylindrical body phantom is six times more efficient than the box case.

The above results show the satisfactory robustness of the design versus the variation of the surrounding environmental 


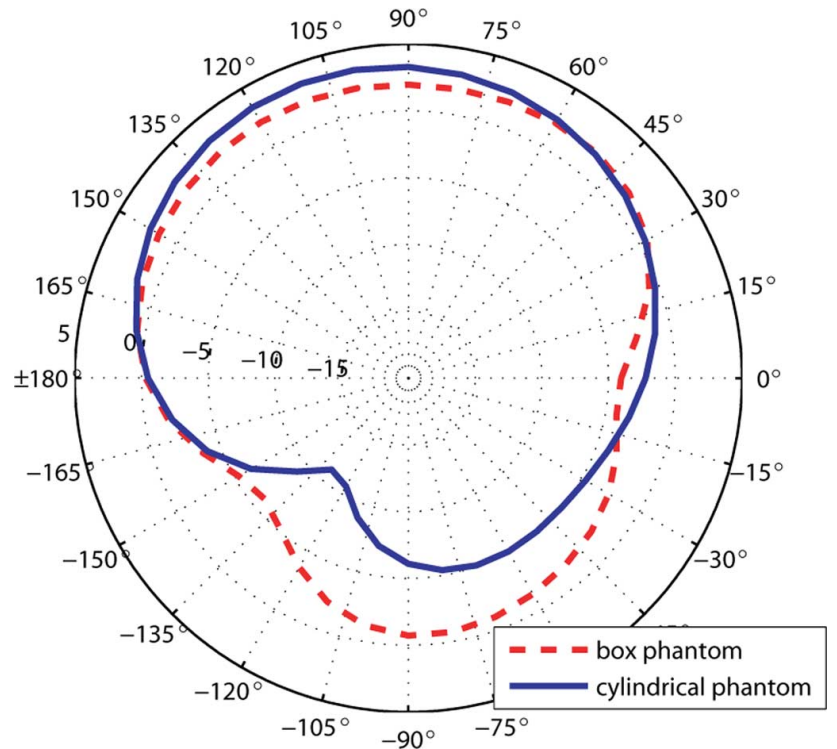

Fig. 12. Simulated radiation patterns $[\mathrm{dBi}]$ on the horizontal plane when the radiator is inserted in the box and cylindrical body phantoms at $404.5 \mathrm{MHz}$. The origin of the coordinate system (shown in Fig. 5(a)) is always placed at the center of the antenna [38].

conditions, as well as the suitability of the chosen cylindrical phantom dimensions for the targeted application. Hence, quite stable performances can be expected for realistic implant locations of the whole integrated telemetry system.

Specific absorption rate (SAR) was computed at the transmitting frequency, i.e., in the MedRadio band. With a mass density equal to $1.0410^{3} \mathrm{~kg} / \mathrm{m}^{3}$ [11], we evaluated the peak spatial averaged 1-g SAR at the resonance frequency of $407 \mathrm{MHz}$ in the equivalent head phantom, in accordance with [36]. The obtained value, with a $1 \mathrm{~W}$ input power, is $289 \mathrm{~W} / \mathrm{kg}$. This implies that the antenna can be fed with signal up to $5.5 \mathrm{~mW}(7.4 \mathrm{dBm})$ and still meet the IEEE recommended value of $1.6 \mathrm{~W} / \mathrm{kg}$ per $1 \mathrm{~g}$ averaging [37]. It is worth noting that the input power of the entire system [17], [18] is less than $0 \mathrm{dBm}$, thus complying with safety requirements.

\section{REALIZATION}

Fig. 13 shows the built implantable antenna and its housing. The manufacturing of ROGER TMM substrates followed standard microstrip fabrication procedures. The assembling (stacking) of the pyramidal geometry of Fig. 3, connected by vertical copper-beryllium pieces, was ensured by a two-component epoxy adhesive. Note that the resonance frequency of the antenna is also affected by the adhesive $\left(\varepsilon_{r}^{\prime}=3, \tan \delta=0.001\right.$, thickness of $35 \mu \mathrm{m}$ ) [32]. The same glue was used to fix the multilayered structure to the conformal ground plane. The latter consists of a coated PEEK piece with the use of a copper foil $50 \mu \mathrm{m}$ thick. The whole construction process is rather delicate but it does still allow good repeatability, as discussed in Section V-B. The prototype weights $2.54 \mathrm{~g}$ including housing, without batteries.

Following [23] and [39], we realized two liquid solutions to mimic the equivalent body models. Dielectric properties were measured with the HP dielectric probe kit 85070 E. Table IV

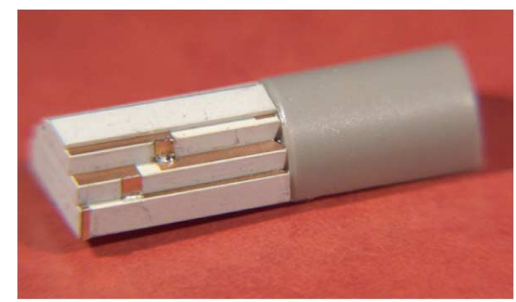

(a)

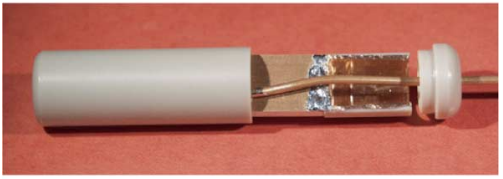

(b)

Fig. 13. Manufactured prototype: (a) multilayered spiral design with the conformal ground plane and (b) final prototype assembling including housing and closing cap. The feeding coaxial cable is present only for testing purpose.

TABLE IV

Dielectric Properties of the Equivalent Muscle Body Phantoms

\begin{tabular}{l|l|l}
\hline Frequency & Target values [31] & Measured values \\
\hline \hline MedRadio & $\varepsilon_{r}^{\prime}=57.10$ & $\varepsilon_{r}^{\prime}=57.36$ \\
{$[23]$} & $\tan \delta=0.622$ & $\tan \delta=0.580$ \\
\hline ISM, $2.45 \mathrm{GHz}$ & $\varepsilon_{r}^{\prime}=52.73$ & $\varepsilon_{r}^{\prime}=53.76$ \\
{$[39]$} & $\tan \delta=0.242$ & $\tan \delta=0.241$ \\
\hline
\end{tabular}

presents targeted and experimental values showing a satisfactory agreement between them.

\section{Measurements}

Experimental results of three realized antennas are described in this section. All the radiators were measured in the absence of the active components. After the realization and characterization of the first prototype, two more radiators were built to improve the calibration of the electromagnetic simulation and, consequently, the EM performance of the model itself. Finally, the importance of the presence of a feeding coaxial cable (and possible erroneous results) is described.

\section{A. First Prototype}

Fig. 14(a) depicts the satisfactory match between prediction and experiment in the MedRadio band.

The comparison between simulated and measured performances in the ISM band is illustrated in Fig. 14(b). The experimental result shows how the frequency behavior is still useful $\left(\left|S_{11}(f)\right|\right.$ equals to $-10 \mathrm{~dB}$ at $\left.2.40 \mathrm{GHz}\right)$ despite a remarkable difference from the targeted characteristics. As presented in Section IV, discrepancy was mainly caused by the difference between the dielectric properties of simulated and real materials.

The exact placement of the antenna inside the body phantom, the feeding coaxial cable (as further detailed in Section V-C) and the liquid phantom itself do influence and increase the difficulty of radiation measurement in the anechoic chamber. Therefore, only horizontal radiation pattern measurement was performed 


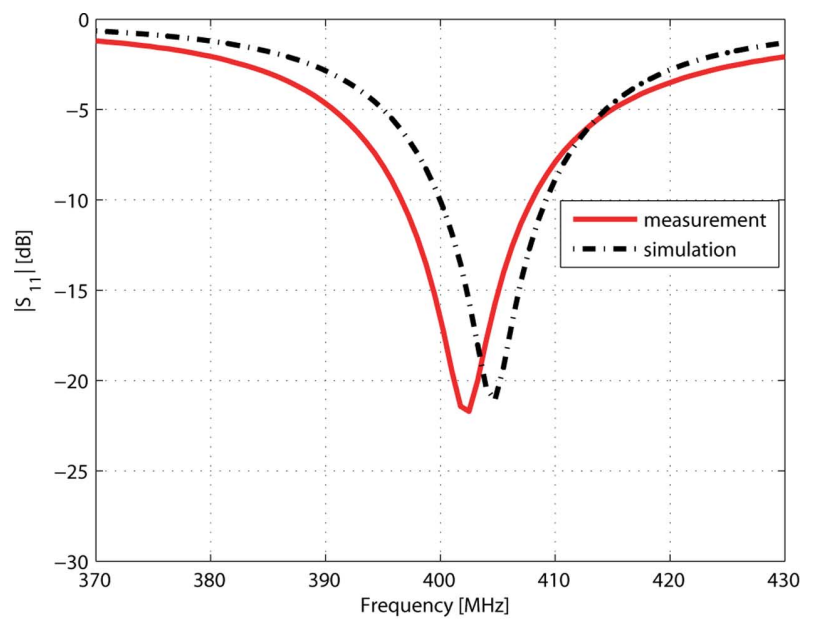

(a)

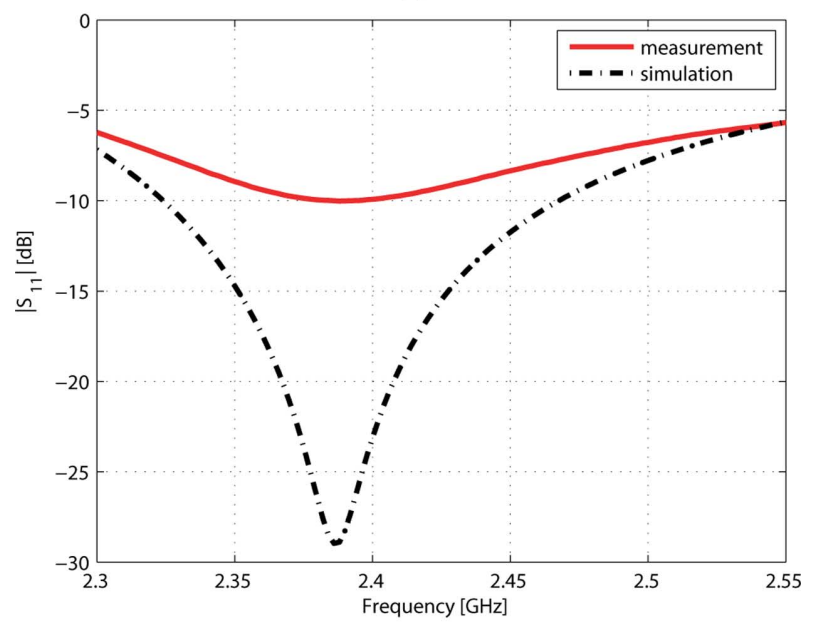

(b)

Fig. 14. Simulated and measured $\left|S_{11}(f)\right|$ : (a) MedRadio and (b) ISM bands. Measurement in the MedRadio band considers the de-embedding of the feeding cable effect.

in the ISM band, as reported in Fig. 15, obtaining an acceptable agreement with theoretical predictions.

\section{B. Improved Prototypes}

The first experimental results allowed the improvement of the calibration of the electromagnetic simulation. The numerical analysis was modified as follows. First, different adhesive dielectric properties $\left(\varepsilon_{r}^{\prime}=4, \tan \delta=0.001\right)$ and thickness (30 $\mu \mathrm{m})$ were considered in the ISM band. The conductivity of vertical copper-beryllium metallizations (see Fig. 3) was set to $\sigma=14 \cdot 10^{6} \mathrm{~S} / \mathrm{m}$ while copper conductivity was reduced to $29 \cdot 10^{6} \mathrm{~S} / \mathrm{m}$. Table $\mathrm{V}$ reports the geometrical modifications. The final design has a total length of $32.1 \mathrm{~mm}$.

Simulated and measured $\left|S_{11}(f)\right|$ are reported in Fig. 16. Maximum frequency deviations of $1 \%$ and $1.3 \%$ are found in the MedRadio and the ISM bands, respectively. Desired matching, that is better than $-10 \mathrm{~dB}$, is achieved for the two working frequencies. The close match found in the ISM band shows the importance of the aforementioned modifications. The new design differs only slightly from the first one (gain $=-29.4,-17.7 \mathrm{dBi}$ directivity $=3.5,4.4 \mathrm{dBi}$, rad. efficiency

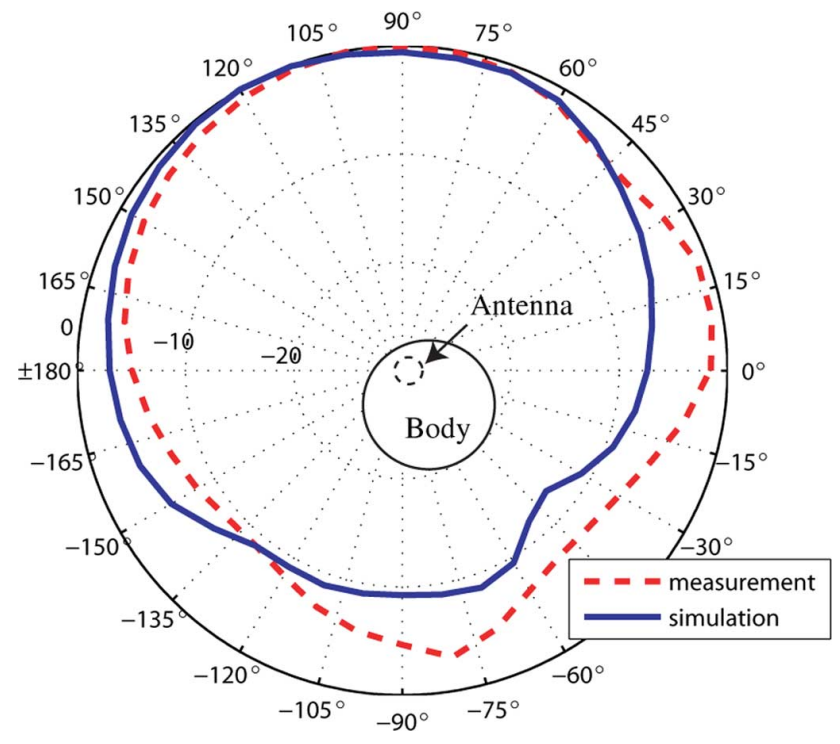

Fig. 15. Simulated and measured normalized radiation patterns $[\mathrm{dB}]$ on the horizontal plane (vertical polarization) at the measured resonant frequency (i.e., $2.3945 \mathrm{GHz}$ ). Maximum value corresponds to $4.2 \mathrm{dBi}$. Cylindrical body phantom and antenna relative positions are indicated at the center of the diagram.

TABLE V

VALUES OF THE PARAMETERS, INDICATED IN FIGS. 3-7, THAT DIFFER FROM TABLE II FOR THE FINAL REALIZATIONS

\begin{tabular}{l|c||l|c}
\hline Parameter & Value $[\mathrm{mm}]$ & Parameter & Value [mm] \\
\hline \hline $\mathrm{sub}_{\mathrm{w} 4}$ & 2.900 & $\mathrm{~h}_{\mathrm{g}}$ & 10.650 \\
\hline $\mathrm{s}_{1}$ & 1.600 & $\mathrm{r}_{\mathrm{g}}$ & 3.550 \\
\hline
\end{tabular}

$=0.051,0.605 \%$ in the MedRadio and ISM band, respectively), hence results about radiation performances, robustness against of the presence of batteries and effect of different body phantoms are not reported to avoid redundancy.

\section{Matching Measurements}

A feeding coaxial cable with ferrite bead choke was used as illustrated in Fig. 17. While the cable presence was not found to influence the radiator in the ISM band, its de-embedding was mandatory when the antenna is electrically smaller, i.e., for the MedRadio measurements, [40], [41]. In order to to better control the unwanted effects due to the cable presence, let us define four different setups, namely:

- case 1: the coaxial cable is in direct contact with the body phantom;

- case 2: a vacuum cylindrical shell surrounds the cable;

- case 3: the depth of insertion of the antenna into the body phantom is reduced (this frees the cable from the body phantom);

- case 4: the desired internal excitation is simulated.

For an easier comprehension case 2 and case 3 are depicted in Fig. 17.

Simulated reflection coefficients for the four setups are reported in Fig. 18. These results show that there exists a large coupling between the currents flowing on the external metallization of the cable [40] and the body phantom. In fact, by inserting the antenna and the cable directly into the body phantom, both 


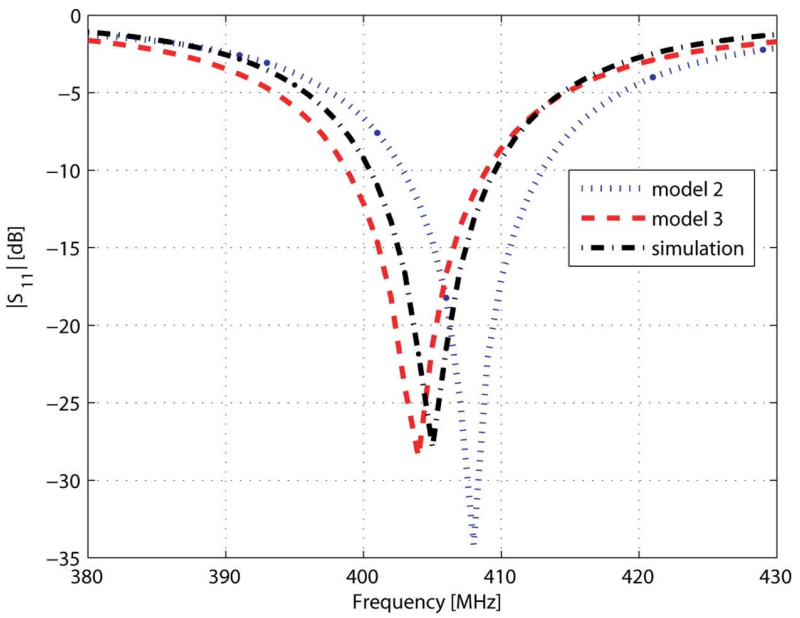

(a)

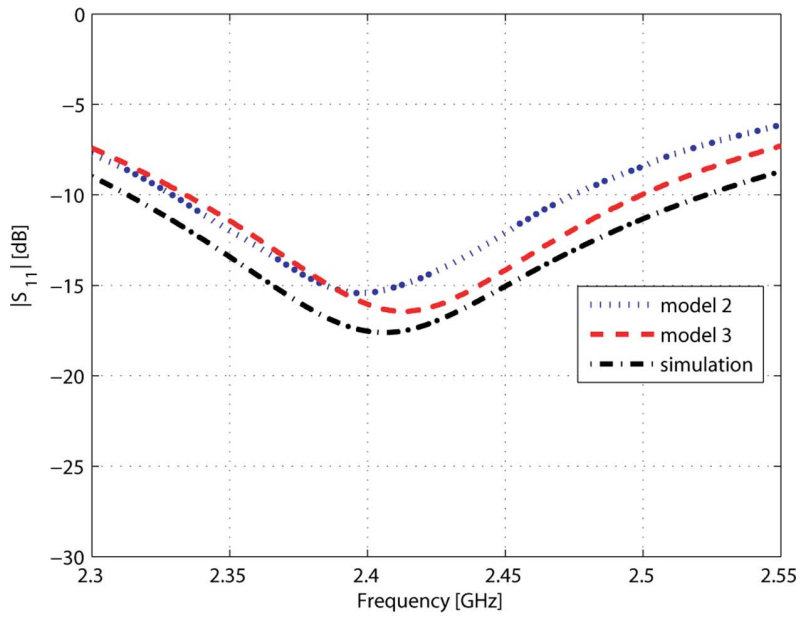

(b)

Fig. 16. Simulated and measured $\left|S_{11}(f)\right|$ : (a) MedRadio and (b) ISM bands. Model 2 and 3 are measured results. Measurements in the MedRadio band avoid the feeding cable effect as described in Section V-C.

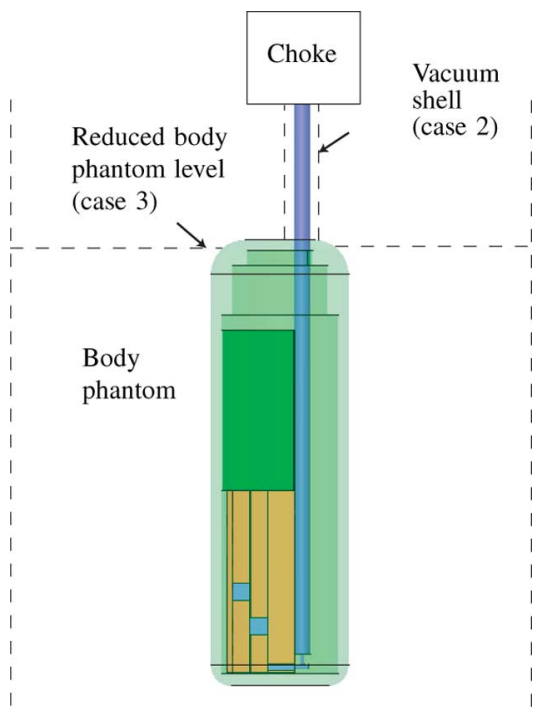

Fig. 17. Description of the different setups in order to understand how to mitigate the effect of the feeding cable. Dashed lines indicate the cylindrical body phantom.

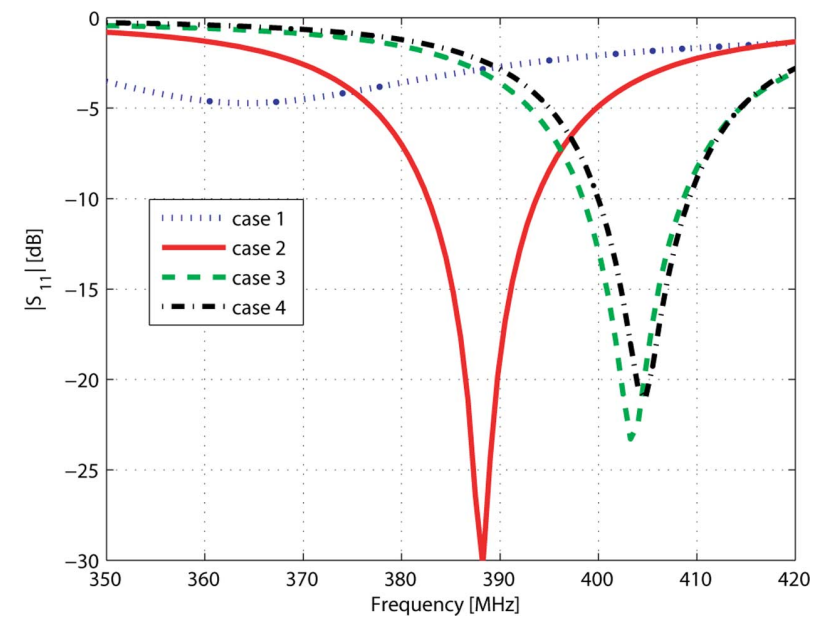

Fig. 18. Simulated $\left|S_{11}(f)\right|$ for case 12,3 and 4 setups (first prototype). In the case 2 condition, the feeding cable is surrounded by a vacuum cylinder $0.3 \mathrm{~mm}$ larger.

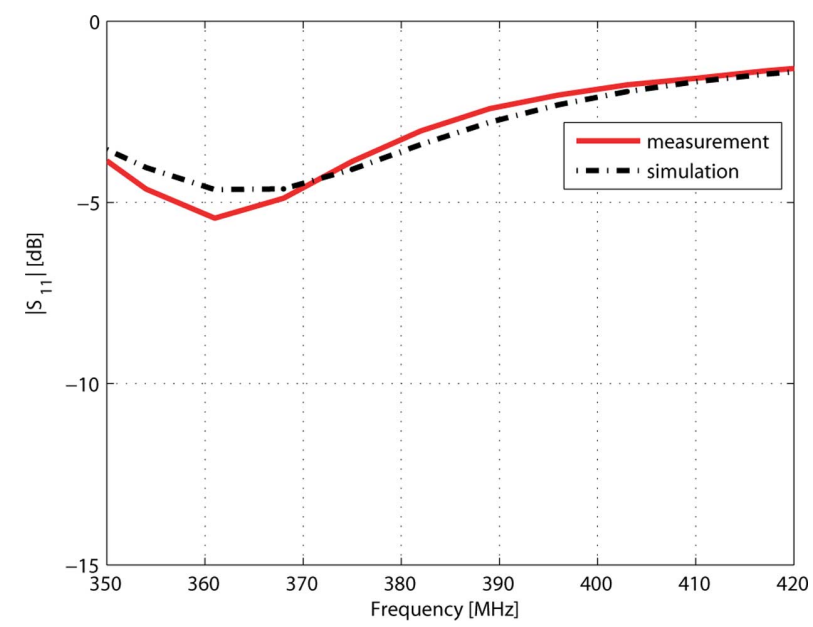

Fig. 19. Comparison of simulated and measured $\left|S_{11}(f)\right|$ in the MedRadio band (for the first prototype) considering the feeding coaxial cable in direct contact with the body model (i.e., case 1).

simulated and measured $\left|S_{11}(f)\right|$ depicted in Fig. 19 are far from the desired performance reported in Fig. 8(a). One can appreciate that case 3 is in close agreement with the desired case 4. The former is the setup corresponding to the results reported in Figs. 14 and 16.

\section{CONCLUSION}

The design procedure, realization and measurements of a miniature conformal antenna for implantable telemetry applications were described. The radiator has dual band capability working in both the MedRadio and the ISM (2.4-2.5 GHz) bands. Physical constraints and EM requirements were discussed in order to set the goals for a successful design.

The design procedure included first numerical analysis in free space to properly choose the antenna typology given the available volume. Further on, the excitation area was set to comply with the physical constraints and we arranged accordingly the selected multilayered spiral typology. Finally, all the dielectric materials and the body phantom were introduced in the numerical analysis. Optimization of the stacked spiral design allowed 
to achieve the targeted performances. The design procedure, albeit focusing on the MedRadio frequency spectrum, provided adequate characteristics for the ISM band as well. Fifty Ohms input impedances were targeted for both working frequencies. Different values could be selected to match specific integrated circuit requirements at the early stage of the design procedure. Obviously, this would call for a re-arrangement of the chosen antenna design.

The radiator takes into account the presence of the bio-compatible insulation, the electronics and the power supply. Its housing includes a specific volume for the monitoring sensors, or bio-actuators. The impact of the presence of active components was computed to confirm the robustness of the design. Indeed, the design is suitable for the realization of a complete implantable device with wireless telemetry capability.

A homogeneous cylindrical body phantom was used for the numerical and experimental analysis. The rough approximation does reduce the simulation time and it provides standard (and easy to realize) conditions for the radiator measurements. We also evaluated the effects of three different body phantoms. This investigation provided insights about the sensitivity of the design versus different implant locations.

Building issues and measurement aspects were described. The feeding coaxial cable effect was found to deeply affect the measured performance in the MedRadio band. A Solution to mitigate this effect was presented. The realization of a first prototype allowed a better calibration of the electromagnetic simulation and, thus, the improvement of the model itself. Two more antennas were designed and fabricated obtaining the desired performances and confirming the good repeatability of the manufacturing process. The final structure (diameter: 10 $\mathrm{mm}$, height: $32.1 \mathrm{~mm}$ ) occupies a volume of $2477 \mathrm{~mm}^{3}$; it is worth noting that less than fourth of it (approximately 24\%) is allocated to the antenna.

Radiation performances (maximum gain equal to -28.8 and $-18.5 \mathrm{dBi}$ in the MedRadio and the ISM band, respectively) fulfill the initial requirements providing robust communication in a $2 \mathrm{~m}$ distance [24]. The antenna is currently being integrated with the power supply and the necessary electronic components [17] representing a complete implantable telemetry system for in-vitro and in-vivo testing. Results, including medical considerations, will be presented in the future. Preliminary experiments confirm the radiation characteristics of the proposed radiator and they show encouraging performances with reading distances up to 10 and $5 \mathrm{~m}$ in the MedRadio and the ISM band, respectively, [42].

\section{ACKNOWLEDGMENT}

The authors would like to thank P. Vosseler and M. Leitos (ACI-EPFL) for all the useful discussions about the mechanical aspects and the realization of the presented prototypes and A. Merli for proofreading the manuscript.

\section{REFERENCES}

[1] D. Panescu, "Emerging technologies [wireless communication systems for implantable medical devices]," IEEE Eng. Med. Biol. Mag., vol. 27, no. 2, pp. 96-101, Mar. 2008.

[2] Medical Implanted Communication System (MICS), FCC Std. CFR, Part 95, 2009

[3] T. Dissanayake, K. P. Esselle, and M. R. Yuce, "Dielectric loaded impedance matching for wideband implanted antennas," IEEE Trans. Microwave Theory Tech., vol. 57, no. 10, pp. 2480-2487, Oct. 2009.
[4] P. M. Izdebski, H. Rajagopalan, and Y. Rahmat-Samii, "Conformal ingestible capsule antenna: A novel chandelier meandered design," IEEE Trans. Antennas Propag., vol. 57, no. 4, pp. 900-909, Apr. 2009.

[5] N. Haga, K. Saito, M. Takahashi, and K. Ito, "Characteristics of cavity slot antenna for body-area networks," IEEE Trans. Antennas Propag., vol. 57, no. 4, pp. 837-843, Apr. 2009.

[6] W. Xia, K. Saito, M. Takahashi, and K. Ito, "Performances of an implanted cavity slot antenna embedded in the human arm," IEEE Trans. Antennas Propag., vol. 57, no. 4, pp. 894-899, Apr. 2009.

[7] R. Warty, M. R. Tofighi, U. Kawoos, and A. Rosen, "Characterization of implantable antennas for intracranial pressure monitoring: Reflection by and transmission through a scalp phantom," IEEE Trans. Microwave Theory Tech., vol. 56, no. 10, pp. 2366-2376, Oct. 2008.

[8] U. Kawoos, M.-R. Tofighi, R. Warty, F. A. Kralick, and A. Rosen, "In-vitro and in-vivo trans-scalp evaluation of an intracranial pressure implant at $2.4 \mathrm{ghz}$, , IEEE Trans. Microwave Theory Tech., vol. 56, no. 10, pp. 2356-2365, Oct. 2008.

[9] K. Gosalia, G. Lazzi, and M. Humayun, "Investigation of a microwave data telemetry link for a retinal prosthesis," IEEE Trans. Microwave Theory Tech., vol. 52, no. 8, pp. 1925-1933, Aug. 2004.

[10] K. Gosalia, M. S. Humayun, and G. Lazzi, "Impedance matching and implementation of planar space-filling dipoles as intraocular implanted antennas in a retinal prosthesis," IEEE Trans. Antennas Propag., vol. 53 , no. 8, pp. 2365-2373, Aug. 2005.

[11] J. Kim and Y. Rahmat-Samii, "Implanted antennas inside a human body: Simulations, designs, and characterizations," IEEE Trans. Microwave Theory Tech., vol. 52, no. 8, pp. 1934-1943, Aug. 2004.

[12] J. Kim and Y. Rahmat-Samii, "Planar inverted-f antennas on implantable medical devices: Meandered type versus spiral type," Microw. Opt. Technol. Lett., vol. 48, no. 3, pp. 567-572, 2006.

[13] P. Soontornpipit, C. Furse, and Y. C. Chung, "Design of implantable microstrip antenna for communication with medical implants," IEEE Trans. Microwave Theory Tech., vol. 52, no. 8, pp. 1944-1951, Aug. 2004.

[14] P. Soontornpipit, C. M. Furse, and Y. C. Chung, "Miniaturized biocompatible microstrip antenna using genetic algorithm," IEEE Trans. Antennas Propag., vol. 53, no. 6, pp. 1939-1945, Jun. 2005.

[15] T. Karacolak, A. Z. Hood, and E. Topsakal, "Design of a dual-band implantable antenna and development of skin mimicking gels for continuous glucose monitoring," IEEE Trans. Microwave Theory Tech. vol. 56, no. 4, pp. 1001-1008, Apr. 2008.

[16] T. Karacolak, R. Cooper, and E. Topsakal, "Electrical properties of rat skin and design of implantable antennas for medical wireless telemetry," IEEE Trans. Antennas Propag., vol. 57, no. 9, pp. 2806-2812, Sep. 2009.

[17] L. Bolomey, E. Meurville, and P. Ryser, "Implantable ultra-low power DSP-based system for a miniature chemico-rheological biosensor," in Proc. Eurosensors XXIII conf., 2009, pp. 1235-1238.

[18] L. Bolomey, F. Merli, E. Meurville, J.-F. Zürcher, and A. Skrivervik, "Telemetry system for sensing applications in lossy media," France Patent Request 00335/10, Mar. 11, 2010.

[19] "Automated characterization of dextran/concanavalin a mixtures-a study of sensitivity and temperature dependence at low viscosity as basis for an implantable glucose sensor," Sensors Act. B: Chem., vol. 146 , no. 1 , pp. $1-7,2010$

[20] A. Barraud, "Molecular selective interface for an implantable glucose sensor based on the viscosity variation of a sensitive fluid containing Dextran and Concanavalin A," Ph.D. dissertation, EPFL, Lausanne, 2008.

[21] Handbook of Materials for Medical Device. Materials Park, OH: ASM international, 2003, ch. 1.

[22] F. Merli, B. Fuchs, J. R. Mosig, and A. K. Skrivervik, "The effect of insulating layers on the performance of implanted antennas," IEEE Trans. Antennas Propag., vol. 59, no. 1, pp. 21-31, 2011.

[23] P. S. Hall and Y. Hao, Antennas and Propagation for Body-Centric Wireless Communications. Norwood, MA: Artech House, 2006, ch. 9.

[24] P. D. Bradley, "An ultra low power, high performance medical implant communication system (MICS) transceiver for implantable devices," in Proc. IEEE Biomedical Circuits and Systems Conf. BioCAS 2006, Nov. 2006, pp. 158-161.

[25] W. G. Scanlon, B. Burns, and N. E. Evans, "Radiowave propagation from a tissue-implanted source at $418 \mathrm{MHz}$ and $916.5 \mathrm{MHz}$," IEEE Trans. Biomed. Eng., vol. 47, no. 4, pp. 527-534, Apr. 2000.

[26] L. C. Chirwa, P. A. Hammond, S. Roy, and D. R. S. Cumming, "Electromagnetic radiation from ingested sources in the human intestine between $150 \mathrm{MHz}$ and $1.2 \mathrm{GHz}$," IEEE Trans. Biomed. Eng., vol. 50, no. 4, pp. 484-492, Apr. 2003. 
[27] K. Ito, "Human body phantoms for evaluation of wearable and implantable antennas," in Proc. of the 2nd Eur. Conf. on Antennas and Propagation (EuCAP 2007), Edinburgh, Scotland, U.K., Nov. 2007.

[28] T. Takimoto, T. Onishi, K. Saito, S. Takahashi, M. Uebayashi, and K. Ito, "Characteristics of biological tissue equivalent phantoms applied to UWB communications," Electron. Commun. Jpn., vol. 90, no. 5, pp. 48-55, 2007.

[29] Y. Okano, K. Ito, I. Ida, and M. Takahashi, "The sar evaluation method by a combination of thermographic experiments and biological tissueequivalent phantoms," IEEE Trans. Microwave Theory Tech., vol. 48, no. 11, pp. 2094-2103, Nov. 2000

[30] Electromagnetic Compatibility and Radio Spectrum Matters (ERM); Ultra Low Power Active Medical Implants (ULP-AMI) Operating in the $401 \mathrm{MHz}$ to $402 \mathrm{MHz}$ and $405 \mathrm{MHz}$ to $406 \mathrm{MHz}$ Bands; System Reference Document, ETSI Std. TR 102343 V1.1.1, 2004

[31] C. Gabriel, "Compilation of the Dielectric Properties of Body Tissues at RF and Microwave Frequencies," Brooks Air Force Base, TX, 1996, Tech. Rep. Report N.AL/OE-TR-

[32] J. Abadia, F. Merli, J.-F. Zürcher, J. R. Mosig, and A. K. Skrivervik, "3D-spiral small antenna for biomedical transmission operating within the MICS band," Radioengineering, vol. 18, no. 4, pp. 359-367, Dec. 2009.

[33] S. Best and J. Morrow, "The effectiveness of space-filling fractal geometry in lowering resonant frequency," IEEE Antennas Wireless Propag. Lett., vol. 1, pp. 112-115, 2002.

[34] S. Best and J. Morrow, "On the significance of current vector alignment in establishing the resonant frequency of small space-filling wire antennas," IEEE Antennas Wireless Propag. Lett., vol. 2, pp. 201-204, 2003.

[35] R. W. P. King and G. S. Smith, Antennas in Matter: Fundamentals, Theory, and Applications, 1st ed. Cambridge, Massachusetts, and London: MIT Press, 1981.

[36] IEEE Recommended Practice for Determining the Peak Spatial-Average Specific Absorption Rate (SAR) in the Human Head From Wireless Communications Devices: Measurement Techniques, IEEE Std. Std 1528, 2003.

[37] Standard for Safety Levels With Respect to Human Exposure to Radio Frequency Electromagnetic Fields, $3 \mathrm{kHz}$ to $300 \mathrm{GHz}$, IEEE Std. Std C95., 1999.

[38] R. Moore, "Effects of a surrounding conducting medium on antenna analysis," IEEE Trans. Antennas Propag., vol. 11, no. 3, pp. 216-225, May 1963

[39] OET Bulletin 65, Edition 97-01, FCC Std. Supplement C, Jun. 2001.

[40] A. K. Skrivervik, J. F. Zürcher, O. Staub, and J. R. Mosig, "PCS antenna design: The challenge of miniaturization," IEEE Antennas Propag. Mag., vol. 43, no. 4, pp. 12-27, Aug. 2001.

[41] F. Merli and A. K. Skrivervik, "Design and measurement considerations for implantable antennas for telemetry applications," in Proc. 4th Eur. Conf. on Antennas and Propagation EuCAP 2010, Apr. 12-16, 2010.

[42] F. Merli, L. Bolomey, E. Meurville, and A. K. Skrivervik, "Dual band antenna for subcutaneous telemetry applications," in Proc. IEEE Antennas and Propagation Society Int. Symp. (APSURSI), 2010, pp. 1-4.

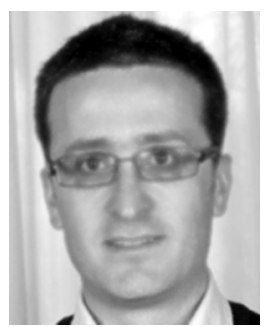

Francesco Merli (M'07) received the Laurea degree (cum laude) in telecommunication engineering from the University of Florence, Florence, Italy, in 2006 and the Ph.D. degree in electrical engineering from Ecole Polytechnique Fédérale de Lausanne (EPFL), in 2011.

His research interests include antenna theory with particular focus to implantable and UWB antennas, spherical wave analysis, biomedical applications, wireless sensing and atomic watch cavities.

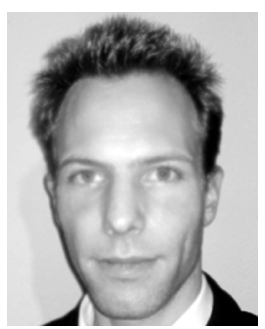

Léandre Bolomey was born in 1980 at Morges (Switzerland). He received the Master and Ph.D. degrees in electrical sciences at the Ecole Polytechnique Fédérale de Lausanne (EPFL) in 2003 and 2010 , respectively.

In 2004 he worked at Xemics (Semtech) as an ASIC Test Engineer and at DspFactory (Onsemi) for the design of a hearing aids analogue front-end. From 2004 to 2005, he worked as an Assistant at the Laboratory of Microengineering for Manufacturing (EPFL). During this period, he participated in a
European project (SPARC) in which he developed an embedded dual-core platform for vision application in the automotive area. He has also worked for a CTI project in which he designed a wearable RF transceiver for a glucose sensor. In 2006, he began his thesis work on "Generic implantable Body Senor Node."

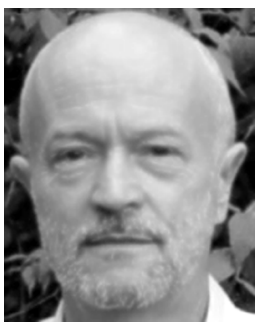

Jean-François Zürcher was born in Vevey, Switzerland, in 1951. He graduated with the degree of Electrical Engineer from Ecole Polytechnique Fédérale de Lausanne (Lausanne Institute of Technology) in 1974.

He is presently employed as a permanent Scientific Associate with the Laboratoire d'Electromagnétisme et d'Acoustique EPFL, where he is the Manager of the microwave laboratory. His main interest lies in the domain of microstrip circuits and antennas. In 1988, he invented the SSFIP concept ("Strip Slot Foam Inverted Patch antenna"), which became a commercial product. He is presently developing instrumentation and techniques for the measurement of near fields of planar structures and microwave materials measurement and imaging.

$\mathrm{He}$ is the author or coauthor of about 125 publications, chapters in books and papers presented at international conferences. He is coauthor of the book Broadband Patch Antennas (Artech, 1995). He holds 8 patents.

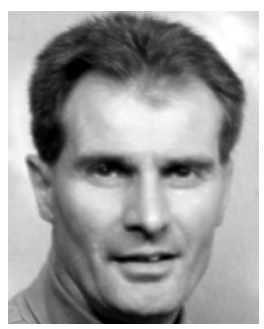

Giancarlo Corradini is a technician in electronics specialized in surface mounted devices. He has worked 18 years in the industry where he was manager of a production unit in the field of hybrid circuits. In 1999, he was hired at the Laboratory of Production for Microtechnics, of the EPFL. He is responsible for the realization of experimental microsystems in thick-film technology as well as microelectronics back-end.

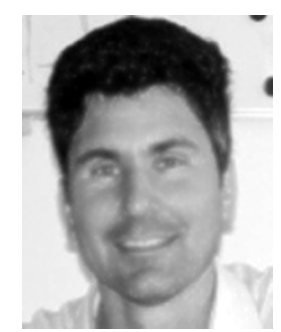

Eric Meurville holds a Master degree in electronics and digital signal processing from the "Conservatoire National des Arts \& Métiers" (CNAM), Paris, France.

Since 1999, he has been working as head of the Product Design Group at the "Laboratoire de Production Microtechnique" of the EPFL and is responsible for advanced research projects in the field of wearable and implantable biomedical devices. During the last 8 years, he has been particularly active in bringing long-term implantable medical devices concepts to commercial realization. From 1995 to 1999, at the Institute of Microtechnology of the University of Neuchâtel, Switzerland, his main field of research was multi-modal biometric access control systems. He was also Project Manager at the "Laboratoire d'Etude des Transmissions Ionosphériques" (LETTI), France, from 1992 to 1995 in the field of over the horizon radars. As software and hardware developer of airborne electronic warfare subsystems, he spent 6 years at Thalès (formerly Dassault Electronics), France, from 1986 to 1992.

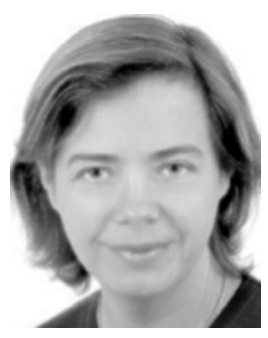

Anja K. Skrivervik received the Electrical Engineering degree and Ph.D. degree from Ecole Polytechnique Fédérale de Lausanne in 1986 and 1992, respectively.

After a passage at the University of Rennes and the Industry, she returned to EPFL as an Assistant Professor in 1996, and is now a "Professeur titulaire" at this institution. Her teaching activities include courses on microwaves and on antennas. Her research activities include electrically small antennas, multi-frequency and ultra wideband antennas, numerical techniques for electromagnetic and microwave and millimeter wave MEMS. She is author or coauthor of more than 100 scientific publications. She is very active in European collaboration and European projects. She is currently the chairperson of the Swiss URSI, the Swiss representative for COST action 297 and a member of the board of the Center for High Speed Wireless Communications of the Swedish Foundation for Strategic Research. 